\title{
Cardiovascular risk factors and incident albuminuria in screen- detected type 2 diabetes
}

\section{Running title: ADDITION-Europe observational analysis}

*DR Webb ${ }^{\mathrm{a}}$, F Zaccardi ${ }^{\mathrm{a}}$, MJ Davies ${ }^{\mathrm{a}}$, SJ Griffin ${ }^{\mathrm{b}, \mathrm{c}}$, NJ Wareham ${ }^{\mathrm{b}}$, RK Simmons ${ }^{\mathrm{b}}$, GE Rutten ${ }^{\mathrm{d}}$, A Sandbaek ${ }^{\mathrm{e}}$, T Lauritzen ${ }^{\mathrm{e}}$, K Borch-Johnsen $^{\mathrm{f}}$, K Khunti

[a] Diabetes Research Centre, University of Leicester, Leicester General Hospital, Gwendolen Road, Leicester, United Kingdom

[b] MRC Epidemiology Unit, University of Cambridge School of Clinical Medicine, Cambridge, United Kingdom

[c] Primary Care Unit, Cambridge Institute of Public Health, Cambridge, UK

[d] Julius Centre for Health Sciences and Primary Care, University Medical Centre Utrecht, Utrecht, Netherlands

[e] School of Public Health, Section of General Practice, University of Aarhus, Aarhus, Denmark

[f] Holbæk Hospital, Holbæk, Denmark

*Corresponding author contact details:

Diabetes Research Centre, University of Leicester, Leicester General Hospital, Gwendolen

Rd, Leicester LE5 4PW

Tel. 004401162588554

Email: david.webb@uhl-tr.nhs.uk

Word Count Abstract: 250; Main Text: 2528

This is the author manuscript accepted for publication and has undergone full peer review but has not been through the copyediting, typesetting, pagination and proofreading process, which may lead to differences between this version and the Version of Record. Please cite this article as doi: $10.1002 / \mathrm{dmrr} .2877$

Observational analysis of the ADDITION-Europe study

This article is protected by copyright. All rights reserved. 


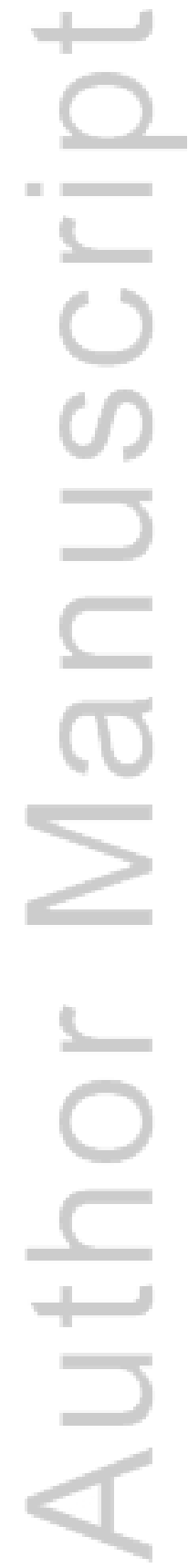

Observational analysis of the ADDITION-Europe study

This article is protected by copyright. All rights reserved. 


\section{Funding}

Individual centres in Denmark, the Netherlands and the United Kingdom were responsible for funding. ADDITION-Denmark has been given unrestricted grants from Novo Nordisk AS, Novo Nordisk Scandinavia AB, Novo Nordisk U.K., AstraZeneca Denmark, Pfizer Denmark, GlaxoSmithKline Pharma Denmark, Servier Denmark A/S, and HemoCue Denmark A/S. Part of the grant from Novo Nordisk was transferred to the other centers. ADDITIONNetherlands was supported by unrestricted grants from Novo Nordisk, GlaxoSmithKline, and Merck. ADDITION-Cambridge was supported by the Wellcome Trust (grant reference no: G061895) and the Medical Research Council (grant reference no: G0001164), the National Institute for Health Research (NIHR) Health Technology Assessment Programme (grantcare.diabetesjournals.org Sandbæk and Associates 2021 reference no: 08/116/300), and National Health Service research and development support funding (including the Primary Care Research and DiabetesResearch Networks), and the NIHR under its Programme Grants for Applied Research scheme (RP-PG-0606-1259). ADDITION-Leicester was supported by the Department of Health and Support for Sciences, the NIHR Health Technology Assessment Programme (grant reference no: 08/116/300), National Health Service research and development support funding (including the Primary Care Research and Diabetes Research Networks Leicestershire, Northamptonshire and Rutland Collaborative for Leadership in Applied Health Research and Care) and the NIHR Leicester Loughborough Lifestyle Biomedical Research Unit. ADDITION-Netherlands was supported by the Julius Centre for Health Sciences and Primary Care, University Medical Centre, Utrecht and by unrestricted grants from Novo Nordisk and Glaxo Smith Kline.

The funding sponsors of the study had no role in the study design, data collection, data analysis, data interpretation, or writing of the report.

Observational analysis of the ADDITION-Europe study

This article is protected by copyright. All rights reserved. 


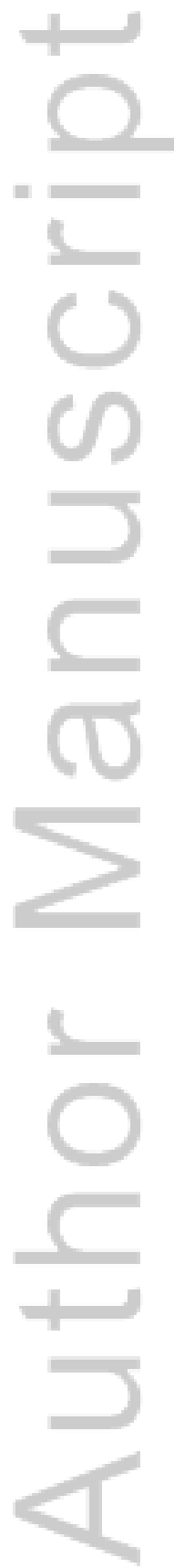

Observational analysis of the ADDITION-Europe study

This article is protected by copyright. All rights reserved. 


\begin{abstract}
Background: It is unclear whether cardiovascular risk factor modification influences the development of renal disease in people with type 2 diabetes identified through screening. We determined predictors of albuminuria five years after a diagnosis of screen-detected diabetes within the ADDITION-Europe study, a pragmatic cardiovascular outcome trial of multifactorial cardiovascular risk management.
\end{abstract}

Methods: In 1,826 participants with newly diagnosed, screen-detected diabetes without albumiuria, we explored associations between risk of new albuminuria $\left(\geq 2.5 \mathrm{mg} \mathrm{mmol}^{-1}\right.$ males and $\geq 3.5 \mathrm{mg} \mathrm{mmol}^{-1}$ females) and: 1) baseline cardio-metabolic risk factors and 2) changes from baseline to one year in systolic blood pressure $(\Delta \mathrm{SBP})$ and glycated haemoglobin $\left(\Delta \mathrm{HbA}_{1 \mathrm{c}}\right)$ using logistic regression.

Results: Albuminuria developed in 268 (15\%) participants; baseline body mass index and active smoking were independently associated with new onset albuminuria in the five years after detection of diabetes. In a model adjusted for age, gender, and baseline $\mathrm{HbA}_{1 \mathrm{c}}$ and blood pressure, a $1 \%$ decrease in $\mathrm{HbA}_{1 \mathrm{c}}$ and $5 \mathrm{mmHg}$ decrease in SBP during the first year were independently associated with lower risks of albuminuria (Odds Ratio (OR), 95\% confidence interval: $0.76,0.62$ to 0.91 and $0.94,0.88$ to 1.01 , respectively). Further adjustment did not materially change these estimates. There was no interaction between $\triangle \mathrm{SBP}$ and $\Delta \mathrm{HBA}_{1 \mathrm{c}}$ in relation to albuminuria risk, suggesting likely additive effects on renal microvascular disease.

Conclusions: Baseline measurements and changes in $\mathrm{HbA}_{1 \mathrm{c}}$ and $\mathrm{SBP}$ a year after diagnosis of diabetes through screening independently associate with new onset albuminuria four years later. Established multifactorial treatment for diabetes applies to cases identified through screening.

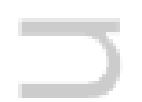

Keywords: Screening, type 2 diabetes, systolic blood pressure, albuminuria, microvascular complications, ADDITION-Europe 


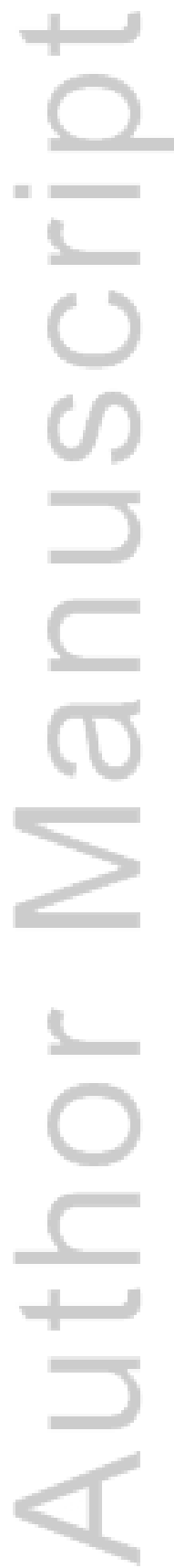

Observational analysis of the ADDITION-Europe study

This article is protected by copyright. All rights reserved. 


\section{Introduction}

People with type 2 diabetes are often simultaneously exposed to a number of cardiovascular disease risk factors in addition to hyperglycaemia, with likely cumulative effects on complications frequency [1,2]. Diabetes case finding through screening theoretically enables identification of risk factors earlier in the disease trajectory, presenting an opportunity for aggressive multifactorial intervention which is not possible until later following other methods of diagnosis [3]. Although a strategy combining optimised blood pressure, glucose and lipids plus anti-platelet therapy has been shown to reduce the frequency of complications in patients with longstanding diabetes and microalbuminuria [4], this has not been demonstrated in "screen-detected" type 2 diabetes [5,6]. Shorter duration of treatment exposure, coupled with a low initial risk of major complications limit attempts to quantify individual or cumulative effects of risk factor modification in this population. It is unknown whether long term effects of initial intensive blood pressure and blood glucose control seen in patients with established diabetes will be similar in screen-detected cases $[7,8]$.

Albuminuria is a biomarker of early chronic kidney disease which independently predicts adverse renal and cardiovascular outcomes in both type 2 diabetes and essential hypertension, although albuminuria does not necessarily indicate the presence of early kidney disease. [9,10]. Its management in hypertensive patients with type 2 diabetes has been shown to be particularly effective if initiated early [11].

We aimed to quantify the association between baseline characteristics, treatment associated changes in risk factors in the year following diagnosis and development of albuminuria over five years in a cohort of people with screen detected type 2 diabetes.

Observational analysis of the ADDITION-Europe study

This article is protected by copyright. All rights reserved. 


\section{Materials and Methods}

\section{Addition Europe}

The study design and rationale of the randomised controlled trial of multifactorial cardiovascular risk modification has been described elsewhere [12]. Briefly, ADDITIONEurope comprises a screening phase and a five year pragmatic, cluster randomized, parallel group intervention trial in four European centers (Denmark; the Netherlands; Cambridge, United Kingdom; and Leicester, United Kingdom). The study was approved by local ethics committees in each center. All participants provided informed consent. 379 general practices took part and were independently randomized to screening plus routine care for diabetes or screening followed by intensive treatment. Screening programs among people aged 40-69 years, without known diabetes, included an oral glucose tolerance test for all individuals in Leicester and a stepwise screening program using random glucose measurements and glycated haemoglobin $\left(\mathrm{HbA}_{1 \mathrm{c}}\right)$ followed by fasting glucose and oral glucose tolerance test in all other centers $[13,14]$. The diagnosis of diabetes was based on World Health Organization criteria. Intervention targets and algorithms for the intensive group were identical in all centers; $\mathrm{HbA}_{1 \mathrm{c}} \leq 7.0 \%$ (53 $\left.\mathrm{mmolmol}^{-1}\right)$, blood pressure $\leq 130 / 70 \mathrm{mmHg}$ and serum total cholesterol $\leq 3.5 \mathrm{mmoll}^{-1}$ [12]. Although treatment targets were specified and classes of drugs recommended, the choice of therapy was made by prescribing clinicians and by patients. Therefore it is not possible to determine independent drug effects on albuminuria development. Routine care practices delivered diabetes care according to national guidelines. All participants, with the exception of those in Denmark for blood pressure, underwent an interim assessment after one year irrespective of treatment allocation. This included standardised measurements of height, weight, blood pressure and $\mathrm{HbA}_{1 \mathrm{c}}$. The results of intensive vs routine care treatment for the primary and secondary outcomes have been previously reported $[5,6]$.

Variables assessment and study outcomes 
Baseline and one year health assessments (completed December 2005) included biochemical, anthropometric, and questionnaire measures, and were undertaken by centrally trained staff following standard operating procedures unaware of study group allocation. Follow-up (five year) examinations took place from September 2008 to the end of December 2009. Biochemical measures were analysed in five regional laboratories at baseline and follow-up. Standardized self-report questionnaires were used to collect information on sociodemographic characteristics (age, sex, and ethnicity), smoking status, and prescribed medication. Information on $\mathrm{HbA}_{1 \mathrm{c}}$ and systolic blood pressure were also available in all centres (other than blood pressure in Denmark) one year after study randomization. Albuminuria (defined as albumin-to-creatinine ratio (ACR) $\geq 2.5 \mathrm{mg} / \mathrm{mmol}$ for males and $\geq 3.5 \mathrm{mg} / \mathrm{mmol}$ for females on timed (morning) sampling [15]) at the end of follow-up was the main outcome for this study. At baseline and follow-up, morning spot urine ACR was measured with a Roche Hitachi 912 chemistry analyzer at Aarhus Hospital (Aarhus, Denmark) and the Steno Diabetes Centre (Gentofte, Denmark), an Olympus AU400 analyser at Addenbrooke's Hospital (Cambridge, United Kingdom) and the Royal Infirmary (Leicester, United Kingdom), and a Roche/Hitachi Modular P analyzer at the SHL Centre for Diagnostic Support in Primary Care (Etten-Leur, Netherlands). Repeated analyses of standardized trial control samples for urine creatinine levels during follow-up confirmed reliability and precision of laboratory methods with coefficients of variation (CVs) $<3.4 \%$ in all laboratories. Analyses of trial and external quality control samples of urine albumin revealed CVs between $2.0 \%$ and $9.8 \%$ in Etten-Leur, Leicester, and Gentofte and $4.9 \%$ and $3.4 \%$ for low and high concentrations, respectively, in Cambridge during the trial testing period.

Statistical analysis

Complete case analyses aimed to explore; 1) independent baseline predictors of 5-year albuminuria in people with diabetes identified by screening and 2) associations between changes in systolic blood pressure and $\mathrm{HbA}_{1 \mathrm{c}}$ from baseline to one year after randomization 
$\left(\triangle \mathrm{SBP}\right.$ and $\Delta \mathrm{HbA}_{1 \mathrm{c}}$, respectively) and subsequent 5-year risk of albuminuria. Association were estimated per $5 \mathrm{mmHg}$ and $1 \%(10.9 \mathrm{mmol} / \mathrm{mol})$ reduction of $\mathrm{SBP}$ and $\mathrm{HbA}_{1 \mathrm{c}}$, respectively, as these were felt to be readily attainable changes commonly seen in clinical practice following a diagnosis of type 2 diabetes.

Participant demographic and clinical characteristics were summarized using means and standard deviation (SD) or frequencies and percentages, as appropriate. Multivariable logistic regression analyses were performed to assess associations between baseline $\mathrm{HbA}_{1 \mathrm{c}}, \mathrm{SBP}$, body mass index and cholesterol measurements and the likelihood of a microvascular renal outcome (presence of albuminuria). This allowed gender specific definitions of albuminuria to be incorporated into a combined logistic analysis. Associations between $\Delta \mathrm{HbA}_{1 \mathrm{c}}$ and $\Delta \mathrm{SBP}$ at one year with risk of albuminuria at the end of follow-up were estimated in logistic regression analyses adjusted for age, gender, baseline $\mathrm{HbA}_{1 \mathrm{c}}$ and baseline SBP (model 1); further adjustment included baseline smoking status (model 2), total cholesterol (model 3), and body mass index (model 4). Following a two-step approach, odds ratios (ORs) were firstly estimated for each centre and then pooled with a fixed-effect meta-analysis according to trial protocol analysis. Centre-specific and overall ORs were displayed using forest plots, and the proportion of variability between centers due to heterogeneity was computed as $I^{2}$. Two-sided statistical tests were performed with Stata 14 (Stata Corp, College Station, TX, USA), and results are reported with $95 \%$ confidence intervals.

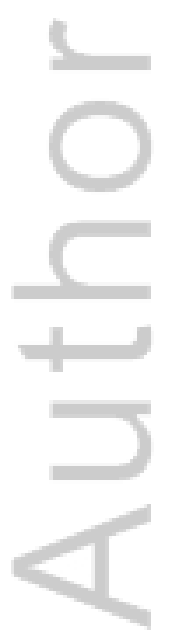




\section{Results}

\section{Study Population}

A total of 3,057 patients were identified with screen-detected type 2 diabetes from four participating centres and entered the trial phase of the study. Participants with prevalent albuminuria at baseline $(n=547)$, or with missing data at baseline $(n=312)$ or follow-up $(n=372)$, were excluded, leaving a total of 1,826 for this observational cohort analysis.

\section{Baseline and follow up characteristics}

At baseline, mean (SD) age was 59.9 (6.9) years old, systolic blood pressure 147 (20) $\mathrm{mmHg}$, $\mathrm{HbA}_{1 \mathrm{c}} 6.9 \%$ (1.4) $\left[52 \mathrm{mmol} \mathrm{mol}^{-1}\right.$ (16)], and eGFR 75.0 (16.1) $\mathrm{mL} / \mathrm{min} / 1.73 \mathrm{~m}^{2} .57 \%$ were males and 25\% were current smokers (Table 1). After a mean (SD) follow-up of 5.3 (1.6) years, eGFR was $80.8(19.5) \mathrm{mL} / \mathrm{min} / 1.73 \mathrm{~m}^{2}$ and $268(15 \%)$ cases of albuminuria were recorded. At one year follow-up, mean $\mathrm{HbA}_{1 \mathrm{c}}$ values were $0.6 \%\left(6.5 \mathrm{mmol} \mathrm{mol}{ }^{-1}\right)$ and $0.5 \%$ $\left(6.0 \mathrm{mmol} \mathrm{mol}^{-1}\right)$ lower in the subsequently determined cases and non-cases of albuminuria, respectively. Similarly, systolic blood pressure was 11 (24) mmHg lower in cases and 12 (21) $\mathrm{mmHg}$ lower in non-cases (Table 1).

In a multivariable analysis, baseline age, active smoking and body mass index were positively associated with albuminuria. Male gender but not baseline total plasma cholesterol, $\mathrm{HbA}_{1 \mathrm{c}}$ or SBP was also associated with development of albuminuria (Table 2).

Change in $\mathrm{HbA}_{1 c}$ and systolic blood pressure between baseline and one year follow up and albuminuria risk

In analyses adjusted for age, gender, baseline $\mathrm{HbA}_{1 \mathrm{c}}$, and baseline blood pressure (1597 participants, 236 incident cases) a one unit (1\% or $10.9 \mathrm{mmol} / \mathrm{mol})$ decrease in $\Delta \mathrm{HbA}_{1 \mathrm{c}}$ was associated with a $24 \%$ lower risk of albuminuria at five years (OR 0.76, 0.62 to 0.91 ). This association persisted after additional adjustment for smoking (model 2), total cholesterol 
(model 3) and body mass index (model 4) (Fig. 1). Moderate heterogeneity was found across centres for all the models. The inclusion of baseline ACR to model 4 did not change the estimate (OR $0.79 ; 0.64$ to 0.98$)$.

In analyses adjusted for age, gender, baseline $\mathrm{HbA}_{1 \mathrm{c}}$, and baseline blood pressure (764 participants, 93 incident cases), a $5 \mathrm{mmHg}$ decrease in $\triangle \mathrm{SBP}$ was associated with a $6 \%$ lower risk of albuminuria at five years (Odds Ratio (OR), 95\% confidence interval: $0.94,0.88$ to 1.00), corresponding to $1 \%$ and $12 \%$ risk reduction in five year albuminuria with a $1 \mathrm{mmHg}$ and $10 \mathrm{mmHg} \triangle \mathrm{SBP}$, respectively assuming a linear relationship. The association was similar after adjustment for smoking, total cholesterol and body mass index (Figure 1) and adding baseline ACR to model 4 (OR $0.93 ; 0.87$ to 0.99 ). Moderate heterogeneity was found across centres for all the models.

Sensitivity analyses demonstrated no statistically significant interaction between $\Delta \mathrm{HBA}_{\mathrm{lc}}$ and $\Delta$ SBP and risk of albuminuria in any model (eg. $p$ for interaction $\geq 0.545$ ).

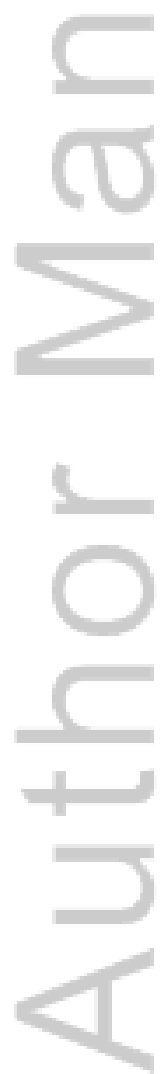




\section{Discussion}

Previous studies have shown that the risk of microvascular complications is significantly reduced by intensive blood glucose or blood pressure control in individuals with established type 2 diabetes, with no obvious threshold across blood pressure or glycated haemoglobin ranges [16-20]. As microvascular disease is linked to duration and initial control of hyperglycaemia, it follows that aggressively intervening earlier in the disease may be advantageous [21]. Albuminuria is an important independent risk factor for cardiovascular mortality in diabetes and its management has been shown to reduce the risk of progressive renal disease $[22,23]$.

We have demonstrated that with the exception of dyslipidaemia, reversible determinants of incipient reno-vascular disease appear similar for patients detected by screening and therefore at an earlier stage of type 2 diabetes. A $1 \%$ reduction in $\mathrm{HbA}_{1 \mathrm{c}}$ was associated with a significant $24 \%$ lower risk of albuminuria five years after diagnosis. A $5 \mathrm{mmHg}$ change in blood pressure within the first year of diagnosis was also associated with a lower risk of this clinically important outcome. This risk reduction is similar to other modelled findings exploring microvascular disease outcomes in patients with type 2 diabetes and the estimated one year cardiovascular risk factor modification is within that expected of current clinical practice.

Whilst we found no association with plasma total cholesterol concentration, previous studies have linked hypertriglyceridemia with diabetes-related renal disease, although these did not adjust for baseline body mass index [24,25]. Epidemiological studies consistently demonstrate that in the general population, individuals who are overweight (BMI 25-29 $\mathrm{kg} / \mathrm{m}^{2}$ ) or obese have an increased risk of chronic kidney disease [26], and this also appears to be the case in this population with early onset diabetes, independent of glucose concentration. The importance of fat mass and its pro-inflammatory and or metabolic sequelae in the pathogenesis of renal disease warrants further investigation. 
Our interaction analyses did not demonstrate any relationship between changes in blood pressure and glucose and 5-year albuminuria risk. Combined intensive blood pressure lowering and glucose control in the ADVANCE (Action in Diabetes and Vascular Disease: Preterax and Diamicron MR Controlled Evaluation) trial reduced the risk of new onset microalbuminuria by approximately $25 \%$ after 4.3 years of follow up [18,19]. The $2 \times 2$ factorial design of ADVANCE allowed independent assessment of risk factor management on outcomes and concluded that blood pressure and blood glucose lowering result in separate, additive effects on renal microvascular disease [27]. Whilst the multifactorial intervention of ADDITION Europe limits the ability to draw firm conclusions in respect to individual treatment strategies, the magnitude of reduction in albuminuria risk associated with blood pressure and blood glucose lowering appears consistent across the studies, and suggests likely benefits from this approach in cases identified through screening.

Observed lack of risk factor interplay in these analyses suggest that either independent (and independently treatable) vasculopathic mechanisms contribute to renal complications in type 2 diabetes irrespective of disease duration or that sample sizes are insufficient to detect statistically meaningful interactions. Although we are unable to definitively exclude any interaction without a much larger and longer study, we are confident that this result supports the current multifactorial treatment paradigm for type 2 diabetes.

The findings of this analysis need to be placed in context with those of the ADDITIONEurope randomised controlled trial [5]. This study concluded that compared to routine care, five years of target driven intensive multifactorial management of patients with type 2 diabetes detected by screening is not associated with significant reductions in the frequency of microvascular events, including microalbuminuria. An explanation for this observation relates to smaller-than-expected differences between the treatment groups, rather than lack of efficacy of the chosen multifactorial treatment approach in screen-detected cases. In fact both intensive and routine care arms of the trial saw reductions in the number of cases of microalbuminuria. Simulation models consistently indicate major benefits are likely to accrue from the early diagnosis and treatment of hyperglycaemia and other cardiovascular risk factors in people with type 2 diabetes [3,28]. 
There are some limitations of this study in addition to the reliance on associative analyses already alluded to. Firstly, an experimental design controlling for individual risk factor exposure may allow stronger causal conclusions to be drawn and it may be important to consider additional lipid indices and/or anthropometrics when constructing models relevant to renal outcomes. Secondly, we opted to perform complete case analyses and did not impute missing data, acknowledging that the lack of availability of one year data in one centre reduced the sample population. Although the number of new cases of albuminuria was sufficient to allow meaningful comparisons, independent effects of particular treatments or drug classes were not possible due to the pragmatic nature of the ADDITION-Europe intervention. We felt albuminuria development in people with diabetes is a clinically significant event worthy of reporting but acknowledge its transitory nature in clinical practice. We did not take into account the possibility of subsequent regression to normoalbuminuria in some cases or the likely importance of other markers of renal disease (eg. eGFR decline). Whilst linking to more patient identifiable outcomes such as end-stage renal or cardiac disease is of relevance, this would require a much longer follow up period and larger sample size. The impact of microvascular disease burden on the development of albuminuria eg. presence of retinopathy and neuropathy, could not be ascertained as these were not quantified at baseline. Despite these caveats we feel that this study improves our understanding of early onset type 2 diabetes, and more importantly the likely effectiveness of widely adopted complication prevention strategies. To our knowledge this is the largest cohort of screened cases of type 2 diabetes, with well defined, repeated measurements allowing statistical approaches which can infer independent associations with clinically important outcomes.

In conclusion, active smoking and body mass index are independently associated with the development of albuminuria in patients with type 2 diabetes identified through screening. Subsequent improvement in blood pressure control a year after diagnosis in these patients is independently associated with lower risk of new onset albuminuria four years later. 


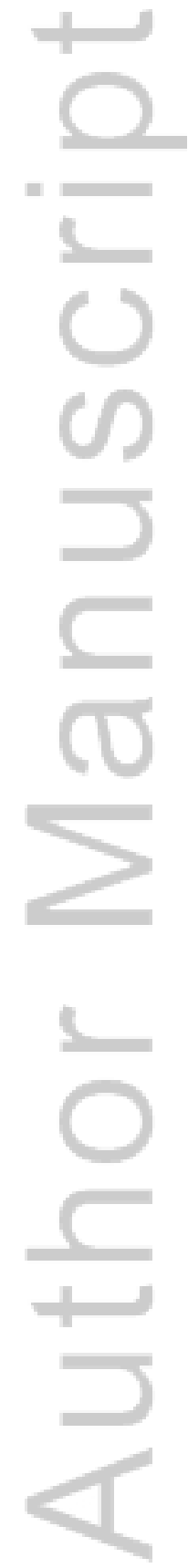

Observational analysis of the ADDITION-Europe study

This article is protected by copyright. All rights reserved. 


\section{Disclosure}

DW has received honoraria for speaking from Sanofi Aventis and travel expenses from Novo Nordisk UK. FZ is supported by an unrestricted grant from Sanofi Aventis. MJD has served on advisory boards for Novo Nordisk, Eli Lilly, Merck, Sharp \& Dohme Bristol-Myers Squib, and Roche; and has received honoraria for speaking from Novo Nordisk, Eli Lilly, Sanofi, Novartis, and Merck, Sharp \& Dohme. SJG has attended an advisory board for Colgate Palmolive; has received honoraria for speaking from Unilever, Eli Lilly, GlaxoSmithKline, Merck, Sharp \& Dohme and Novo Nordisk; and has received travel expenses from Eli Lilly. RS has no financial conflict of interest to declare. GER has served as a consultant and participated on advisory boards for Novo Nordisk and Merck, Sharp \& Dohme and has received honoraria for speaking from Novo Nordisk. AS has received honoraria for speaking and travel expenses from Novo Nordisk Denmark. TL has received research funding from Novo Nordisk, AstraZeneca, Pfizer, Glaxo-SmithKline, Servier, and HemoCue; has received honoraria for speaking from various pharmaceutical companies; and holds stock in Novo Nordisk. KJ was the director of the Steno Diabetes Centre, which is owned by Novo Nordisk, and holds stock in Novo Nordisk. KK has acted as a consultant and speaker for Astra Zeneca, Novartis, Novo Nordisk, Sanofi-Aventis, Lilly, Merck Sharp \& Dohme, Janssen and Boehringer Ingelheim. He has received grants in support of investigator and investigator initiated trials from Astra Zeneca, Novartis, Novo Nordisk, Sanofi-Aventis, Lilly, Boehringer Ingelheim and Merck Sharp \& Dohme and Roche. KK has served on advisory boards for Astra Zeneca, Novartis, Novo Nordisk, Sanofi-Aventis, Lilly, Merck Sharp \& Dohme, Janssen and Boehringer Ingelheim.

\section{Authorship}

DW is a co-investigator of the study and contributed to the design; data acquisition, analysis, and interpretation; drafting of the manuscript; and critical revision of the manuscript for intellectual content. FZ performed data analyses and contributed to the production of all draft manuscripts. K.K., S.J.G., G.E.H.M.R., N.J.W., R.S. A.S., T.L., K.B-J. and M.J.D. are 
principal investigators of ADDITION and contributed to the study design; data acquisition, analysis, and interpretation; and critical revision of the manuscript for intellectual content. DW and KK are the guarantors of this work and, as such, had full access to all the data in the study and take responsibility for the integrity of the data and the accuracy of the data analysis.

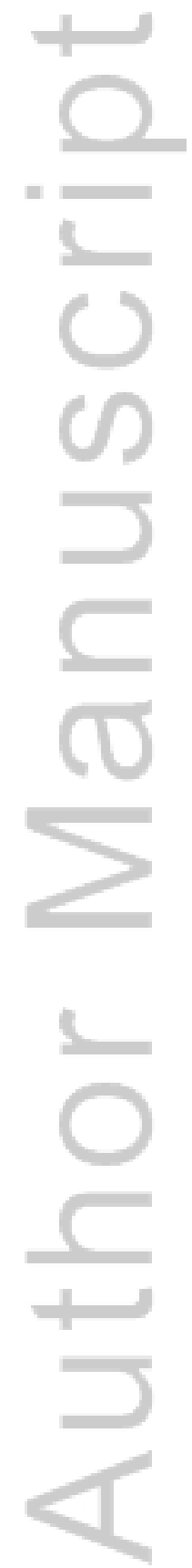




\section{References}

1. Stamler J, Vaccaro O, Neaton JD, et al. Diabetes, other risk factors, and 12-year cardiovascular mortality for men screened in the Multiple Risk Factor Intervention Trial. Diabetes Care 1993; 16:434-444.

2. Stratton IM, Cull CA, Adler AI, et al. Additive effects of glycaemia and blood pressure exposure on risk of complications in type 2 diabetes: a prospective observational study (UKPDS 75). Diabetologia 2006; 49:1761-1769.

3. Herman WH, Ye Wen, Griffin SJ, et al. Early detection and treatment of type 2 diabetes reduces cardiovascular morbidity and mortality: A simulation of results of the Anglo-Danish_Dutch study of intensive treatment in people with screen-detected diabetes in primary care (ADDITION-Europe). Diabetes Care 2015; 38:1449-1455.

4. Gaede $\mathrm{P}$, Lund-Andersen $\mathrm{H}$, Parving $\mathrm{HH}$, et al. Effect of a multifactorial intervention on mortality in type 2 diabetes. New England Journal of Medicine 2008; 358:580-591.

5. Sandbaek A, Griffin SJ, Sharp SJ, et al. Effect of early multifactorial therapy compared with routine care on microvascular outcomes at 5 years in people with screen-detected diabetes: a randomized controlled trial: the ADDITION-Europe Study. Diabetes Care 2014; 37:2015-2023.

6. Griffin SJ, Borch-Johnsen K, Davies MJ, et al. Effect of early intensive multifactorial therapy on 5-year cardiovascular outcomes in individuals with type 2 diabetes detected by screening (ADDITION-Europe): a cluster-randomised trial. Lancet 2011; 378:156-167.

7. The ACCORD study writing group. Nine year effects of 3.7 years of intensive glycaemic control on Cardiovascular outcomes. Diabetes Care 2016; 39:701-708.

8. Zoungas S, Chalmers J, Neal B, et al. ADVANCE-ON Collaborative Group. Followup of blood-pressure lowering and glucose control in type 2 diabetes. New England Journal of Medicine 2014; 371:1392-1406.

9. Gerstein HC, Mann JF, Yi Q, et al. HOPE Study Investigators. Albuminuria and risk of cardiovascular events, death, and heart failure in diabetic and nondiabetic individuals. JAMA 2001; 286:421-426.

10. Jensen JS, Feldt-Rasmussen B, Strandgaard S, et al. Arterial hypertension, microalbuminuria, and risk of ischemic heart disease. Hypertension 2000; 35:898903. 
11. Palmer AJ, Chen R, Valentine WJ, et al. Cost-consequence analysis in a French setting of screening and optimal treatment of nephropathy in hypertensive patients with type 2 diabetes. Diabetes \& Metabolism 2006; 32:69-76.

12. Lauritzen T, Griffin S, Borch-Johnsen K, et al. Anglo-Danish-Dutch Study of Intensive Treatment in People with Screen Detected Diabetes in Primary Care. The ADDITION study: proposed trial of the cost-effectiveness of an intensive multifactorial intervention on morbidity and mortality among people with Type 2 diabetes detected by screening. International Journal of Obesity \& Related Metabolic Disorders: Journal of the International Association for the Study of Obesity 2000; 24

- Suppl 3:S6-11.

13. Webb DR, Khunti K, Srinivasan B, et al. Rationale and design of the ADDITIONLeicester study, a systematic screening programme and randomised controlled trial of multi-factorial cardiovascular risk intervention in people with type 2 diabetes mellitus detected by screening. BMC Trials 2010; 11:16.

14. Van den Donk M, Sandbaek A, Borch-Johnsen K, et al. Screening for Type 2 Diabetes: lessons from the ADDITION-Europe study. Diabetic Medicine 2011; 28:1416-1424.

15. KDIGO 2012 Clinical practice guideline for the evaluation and management of CKD. Kidney International supplements 2013; 3:136-150

16. UK Prospective Diabetes Study (UKPDS) Group. Intensive blood-glucose control with sulphonylureas or insulin compared with conventional treatment and risk of complications in patients with type 2 diabetes (UKPDS 33). Lancet 1998; 352:837853.

17. UK Prospective Diabetes Study (UKPDS) Group. Tight blood pressure control and risk of macrovascular and microvascular complications in type 2 diabetes (UKPDS 38). British Medical Journal 1998; 317:703-713.

18. ADVANCE Collaborative Group; Patel A, MacMahon S, Chalmers J, et al. Intensive blood glucose control and vascular outcomes in patients with type 2 diabetes. New England Journal of Medicine 2008; 358:2560-2572.

19. ADVANCE Collaborative Group; Patel A, MacMahon S, Chalmers J, et al. Effects of a fixed combination of perindopril and indapamide on macrovascular and microvascular outcomes in patients with type 2 diabetes mellitus (the ADVANCE trial): a randomised controlled trial. Lancet 2007; 370:829-840. 
20. Emdin CA, Rahimi K, Neal B, et al. Blood Pressure lowering in Type 2 Diabetes: a systematic review and meta-analysis. JAMA 2015; 313:603-615.

21. Holman RR, Paul SK, Bethel MA, et al. 10-year follow-up of intensive glucose control in type 2 diabetes. New England Journal of Medicine. 2008; 359:1577-1589.

22. KDOQI clinical practice guideline for diabetes and CKD: 2012 update. Am. J. Kidney Disease 2012; 60:850-886.

23. ESH/ESC guidelines for the management of arterial hypertension. Journal of Hypertension 2013; 31:1281-1357.

24. Retnakaran R, Cull CA, Thorne KI, et al. UKPDS Study Group. Risk factors for renal dysfunction in type 2 diabetes: U.K. Prospective Diabetes Study 74. Diabetes 2006; 55:1832-839.

25. Lee PH, Chang HY, Tung CW, et al. Hypertriglyceridemia: an independent risk factor of chronic kidney disease in Taiwanese adults. American Journal of Medical Sciences 2009; 338:185-189.

26. Wang Y, Chen X, Song Y, et al. Association between obesity and kidney disease: a systematic review and meta-analysis. Kidney International 2008; 73:19-33.

27. Zoungas S, de Galan BE, Ninomiya T, et al. Combined effects of routine blood pressure lowering and intensive glucose control on macrovascular and microvascular outcomes in patients with type 2 diabetes: New results from the ADVANCE trial. Diabetes Care 2009: 32:2068-2074.

28. Kahn R, Alperin P, Eddy D, et al. Age at initiation and frequency of screening to detect type 2 diabetes: a cost-effectiveness analysis. Lancet 2010; 375:1365-1374.

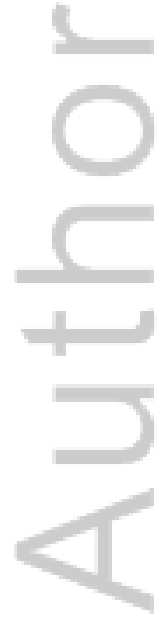




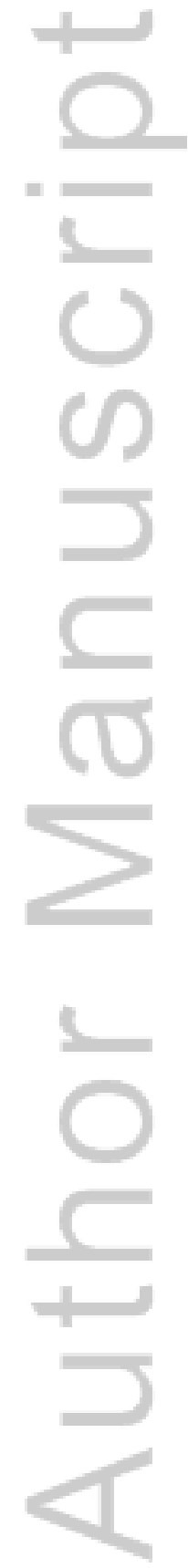

Observational analysis of the ADDITION-Europe study

This article is protected by copyright. All rights reserved. 
Table 1. Baseline and one year characteristics of the ADDITION-Europe population included in the study $(\mathrm{N}=1826)$ according to presence of albuminuria (cases) at 5-year follow up

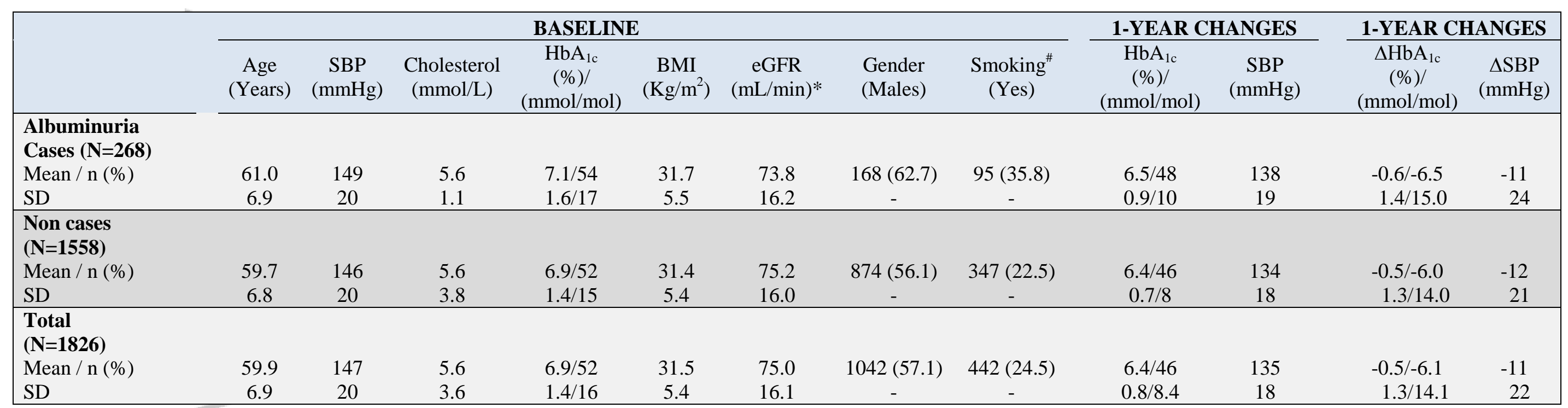

Data are reported as n $(\%)$ for the categorical variables Gender and Smoking

HbA1c: Glycated Haemoglobin; SBP: Systolic Blood Pressure; SD: Standard deviation

$\Delta=1$ year value - baseline value

\# Estimated using the MDRD (Modification of Diet in Renal Disease) formula; values normalised to $1.73 \mathrm{~m}^{2}$

* 21 missing data (18 noncases and 3 cases)

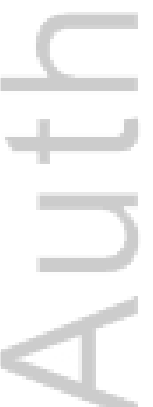

Observational analysis of the ADDITION-Europe study

This article is protected by copyright. All rights reserved. 


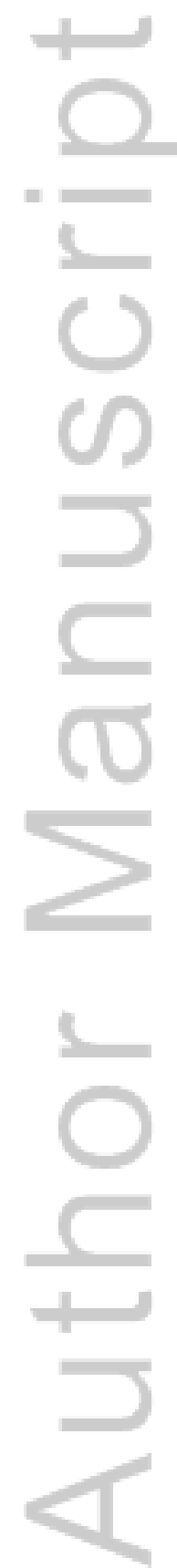

Observational analysis of the ADDITION-Europe study

This article is protected by copyright. All rights reserved. 
Table 2: Multivariable associations of baseline risk factors with the presence of albuminuria at 5-year follow-up

\begin{tabular}{|c|c|c|c|c|}
\hline \multirow[b]{2}{*}{ Risk factor } & \multirow[b]{2}{*}{ OR } & \multicolumn{2}{|c|}{$95 \% \mathrm{CI}$} & \multirow[b]{2}{*}{ p-value } \\
\hline & & Lower & Upper & \\
\hline Age (years) & 1.044 & 1.021 & 1.068 & $<0.001$ \\
\hline Gender (M) & 1.456 & 1.079 & 1.963 & 0.014 \\
\hline Systolic Blood Pressure (mmHg) & 1.003 & 0.996 & 1.010 & 0.425 \\
\hline $\mathrm{HbA}_{1 \mathrm{c}}(\%)$ & 1.097 & 0.998 & 1.207 & 0.054 \\
\hline Smoking (Active) & 1.864 & 1.367 & 2.542 & $<0.001$ \\
\hline Total Cholesterol (mmol/L) & 1.072 & 0.941 & 1.220 & 0.297 \\
\hline Body Mass Index $\left(\mathrm{kg} / \mathrm{m}^{2}\right)$ & 1.045 & 1.017 & 1.074 & 0.001 \\
\hline
\end{tabular}

Odds Ratios (OR) per unit increase of risk factors were estimated for each centre and then combined in a multivariate fixed-effect meta-analysis.

$1 \%$ change $\mathrm{HbA} 1 \mathrm{c}=10.9 \mathrm{mmol} / \mathrm{mol}$ 


\section{Figure Legend}

Figure 1: Association between changes in $\mathrm{HBA}_{1 \mathrm{c}}$ and systolic blood pressure and the presence of 5-year albuminuria

\section{Legend}

Data are combined in fixed-effect meta-analyses DK=Denmark; UK=United Kingdom;

NL=Netherlands Adjustments: Model 1: Age, gender, $\mathrm{HbA}_{1 \mathrm{c}}$, systolic blood pressure; Model 2: Model $1+$ smoking; Model 3: Model 2+ total cholesterol; Model 4: Model $3+$ body mass index $1 \%$ change $\mathrm{HbA} 1 \mathrm{c}=10.9 \mathrm{mmol} / \mathrm{mol}$

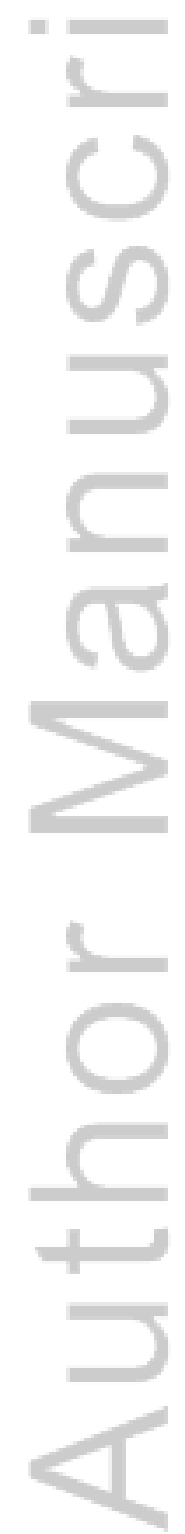


Odds Ratios per $1 \%$ lower $\Delta \mathrm{HbA} 1 \mathrm{c}$

\begin{tabular}{lrr}
\hline & \multicolumn{2}{c}{ Number of } \\
Model & Participants & Cas \\
\hline Model 1 & & \\
DK & 831 & 140 \\
NL & 173 & 30 \\
UK & 593 & 66 \\
Overall & 1597 & 236 \\
& & \\
& & \\
Model 2 & & \\
DK & 825 & 138 \\
NL & 164 & 29 \\
UK & 593 & 66 \\
Overall & 1582 & 233 \\
& & \\
Model 3 & & \\
DK & 779 & 129 \\
NL & 164 & 29 \\
UK & 591 & 66 \\
Overall & 1534 & 224
\end{tabular}

Model 4

DK

NL

UK

Overall

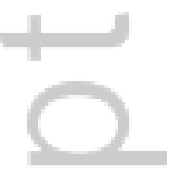



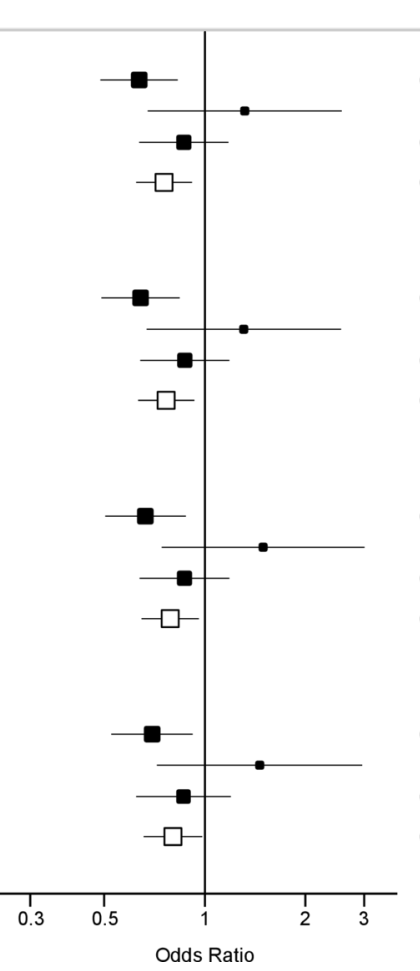

OR $(95 \% \mathrm{Cl})$

$0.64(0.49,0.83)$

$1.32(0.67,2.57)$

$0.87(0.64,1.18)$

$0.76(0.62,0.91)$

$I^{2}=60 \%$

$0.64(0.49,0.84)$

$1.31(0.67,2.55)$

$0.87(0.64,1.18)$

$0.77(0.63,0.93)$

$I^{2}=53 \%$

$0.66(0.50,0.88)$

$1.49(0.74,3.01)$

$0.87(0.64,1.18)$

$0.79(0.65,0.96)$

$I^{2}=56 \%$

$0.69(0.52,0.92)$

$1.46(0.72,2.96)$

$0.86(0.62,1.20)$

$0.80(0.66,0.98)$

$I^{2}=45 \%$
Odds Ratios per $5 \mathrm{mmHg}$ lower $\triangle \mathrm{SBP}$

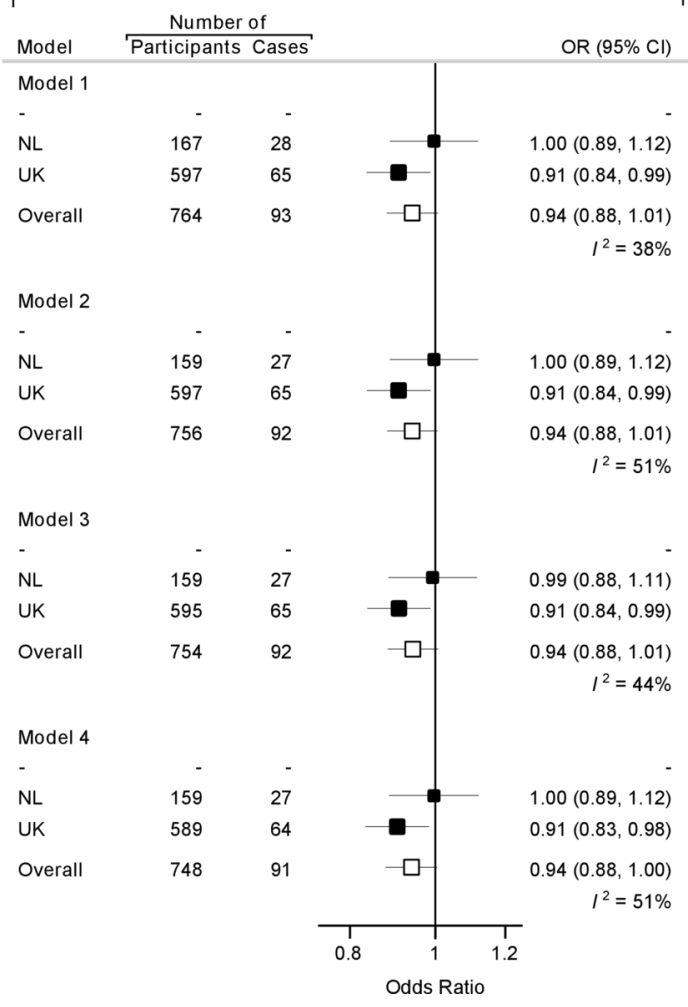

dmrr_2877_f1.eps 


\section{University Library}

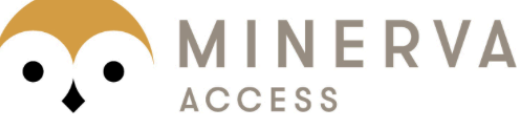

A gateway to Melbourne's research publications

Minerva Access is the Institutional Repository of The University of Melbourne

Author/s:

Webb, DR;Zaccardi, F;Davies, MJ;Griffin, SJ;Wareham, NJ;Simmons, RK;Rutten, GE;Sandbaek, A;Lauritzen, T;Borch-Johnsen, K;Khunti, K

Title:

Cardiovascular risk factors and incident albuminuria in screen-detected type 2 diabetes

Date:

2017-05-01

\section{Citation:}

Webb, D. R., Zaccardi, F., Davies, M. J., Griffin, S. J., Wareham, N. J., Simmons, R. K., Rutten, G. E., Sandbaek, A., Lauritzen, T., Borch-Johnsen, K. \& Khunti, K. (2017).

Cardiovascular risk factors and incident albuminuria in screen-detected type 2 diabetes. DIABETES-METABOLISM RESEARCH AND REVIEWS, 33 (4), https://doi.org/10.1002/ dmrr.2877.

Persistent Link:

http://hdl.handle.net/11343/292595 